\title{
A Proposal for an Electronic Negotiation Platform for Tourism in Low-Density Regions: Characterizing a Functional Analysis and Prototype for the Douro Valley
}

\author{
Luís Cardoso $^{1}$, José Martins ${ }^{1,2}$, Ramiro Gonçalves ${ }^{1,2(\bowtie)}$, \\ Frederico Branco $^{1,2(\bowtie)}$, Fernando Moreira ${ }^{3,4}$, \\ and Manuel Au-Yong-Oliveira ${ }^{5}$ \\ ${ }^{1}$ University of Trás-os-Montes e Alto Douro, 5000-801 Vila Real, Portugal \\ luis29-10-1995@hotmail.com, \\ \{jmartins, ramiro,fbranco\}@utad.pt \\ 2 INESC TEC (coordinated by INESC Porto), Faculty of Engineering, \\ University of Porto, 4200-465 Porto, Portugal \\ 3 Univ Portucalense, Portucalense Institute for Legal Research - IJP, Research \\ on Economics, Management and Information Technologies - REMIT, \\ Porto, Portugal \\ fmoreira@uportu.pt \\ ${ }^{4}$ Universidade Aveiro, IEETA, Aveiro, Portugal \\ 5 GOVCOPP, Department of Economics, Management, Industrial Engineering \\ and Tourism, University of Aveiro, 3810-193 Aveiro, Portugal \\ mao@ua.pt
}

\begin{abstract}
Traditional e-Commerce platforms tend to mimic existing physical store processes in which customers are given the opportunity to purchase only the available products without any type of personal customization or even without the possibility of being allowed to present a desired product/service to which the market might be able to respond. With this in mind, a prototype for an electronic negotiation platform directed at the tourism sector has been developed and focused on Douro Valley tourism operators, products and services. In our opinion this prototype might help to develop new business models drawn from the customers' willingness to have a personal tourism experience and not just something off the shelf.
\end{abstract}

Keywords: e-Commerce platform $\cdot$ Tourism $\cdot$ Negotiation platform e-Commerce prototype $\cdot$ Software analysis and prototyping

\section{Introduction}

The impact of information and communication technologies (ICT) on companies in the various branches of industry has never been greater. In fact, finding a product or service that has not been altered or influenced by ICT in any way is becoming more and more difficult [1]. 
Since the emergence of the Internet, the way business is being conducted has been changing. ICT has opened up new opportunities and threats that have changed traditional ways of doing business. Consequently, the processes involved in various fields such as trade, economy, etc., have also changed [2]. ICTs, in constant evolution, have thus become one of the decisive factors for a good implementation and subsequent competitive positioning of organizations. In this sense, the Internet has affirmed itself as an important channel of communication and commercialization of goods and services.

Since any company can afford the costs associated with its insertion in the Internet/E-Commerce (EC), it has become possible to compete in this global economy, and consequently expose and sell products/services to a wider range of customers.

Without question, with the increasing adoption of EC in the world and its exceptional potential, it is now clearly evident that countries where ICT are more developed have an advantage. EC is beginning to be considered as a new form of business, with extensive scope to create new strategies and business opportunities, either at the level of organizations (it allows for the reduction of costs and process improvements), or at the level of the communication channel with the customer (it allows new sales channels, new products and services, new forms of relationship and new opportunities in new business projects) [3].

In fact, the rapid development of the Internet has created a great opportunity to conduct business activities electronically. Customers can search for information about a product on the web and shop online. However, the price or terms for the goods or services are usually pre-specified by the seller or determined by well-defined procedures such as online auctions.

Although the traditional process of buying and selling on Web platforms is already quite stable, the latest changes in the way consumers approach online searches and purchases of products and services has forced organizations, and by default, EC platforms to change their ways of selling.

As e-commerce begins to become more sophisticated, it becomes necessary for more complex support contracts or business options to be mutually determined (such as negotiating the terms of a tourist trip, including price, date of arrival, date of departure, etc.).

In a world where more and more businesses are being moved to the Internet, disputes also increase in the virtual space, so the demand for trading also stems from the need to resolve a dispute. One solution would be to adjust e-commerce platforms to allow customers not only to buy products/services, but also to negotiate their terms in order to customize them according to their preferences.

In this context, the objective of this research is to achieve a Marketplace ecommerce Web platform, where the customer can propose the products or services he/she would like to have and the suppliers registered for such requests can respond to those proposals. This new form of negotiation and online bidding, in addition to the traditional way of selling, will transform EC platforms into tools that are much better suited to new customers. 


\section{Conceptual Background}

\subsection{Electronic Commerce and Negotiation Platforms}

ICTs, in constant evolution, have become an indispensable tool for conducting business and for achieving effective competitive positions by organizations.

In fact, since the emergence of the Internet, the way to conduct business has been changing quite significantly. Due to the characteristic of ubiquity, associated with the Internet, the market is able to be free of restrictions to physical space as it is possible to make purchases from home, at work, or from any other site, using the technologies of mobile commerce. The result of this feature is a commercial space, that is, a market space that extends beyond traditional frontiers and away from a temporal and geographical location [2].

Based on what has been described, from a consumer's point of view, ubiquity reduces the costs of a transaction (costs of market share). To make transactions, it is no longer necessary to invest time and money on trips to a given market. From the point of view of the negotiator, since almost any company can afford the costs associated with its insertion in the Internet, it becomes possible to compete in this global economy, and consequently expose a firm's products/services to a wider range of clients.

As the global market expands and business and personal relationships are increasingly taking place in an online space, it is also becoming more commonplace and 'normal' to conduct negotiation processes electronically [4].

With the evolution of ICT and the emergence of the Internet, new opportunities for the design and implementation of software capable of supporting negotiators, mediators and arbitrators, have appeared and so currently electronic trading platforms are widely used [5].

Before describing electronic trading systems, it is considered important to first define the trading concept.

A negotiation can be understood as a process of communication between a group of parties, with a conflict of interests or preferences, that aims at reaching an agreement or compromise between the parties [6,7]. Negotiation processes occur in a myriad of ways, being influenced by ethical, cultural, and social circumstances [8].

Electronic Trading refers to negotiation processes that are fully or partially conducted through the use of electronic devices, which use digital channels to carry data [9].

An electronic trading system is a system that uses the Internet to facilitate, organize, support and/or automate trading activities [10,11]. This definition also includes all types of software capable of helping one or more negotiators or mediators, which includes email, chat $[12,13]$, software that combines negotiation and bidding mechanisms [14], among others. Typically, these systems adopt a Web-based design and are deployed on the Internet [15].

According to Braun et al. [8], an electronic trading system must have at least one or more of the following capabilities:

- To support the concession and decision making;

- To support the suggestion of offers and the negotiation of agreements; 
- To support access and the critique of offers while also allowing counter-offers;

- To support the structuring and organization of processes;

- To provide information and knowledge;

- To facilitate and organize communication;

- To assist in the preparation of an agreement;

- To provide access to specialists, mediators or facilitators.

\subsection{Electronic Commerce and Negotiation Platforms Applied to Tourism}

The adoption of ICTs in the tourism sector over the last few years, which represents a strong technological evolution, also motivated a different approach by tourists, who are increasingly sophisticated and who expect more dynamic tourism experiences [13]. It is therefore crucial that tourism organizations adapt their business in a way that keeps them competitive [14].

Contemporary society has made the tourism sector highly information-intensive, as ICT increasingly plays a determining role in the success of industry organizations. The use of ICT in the tourism sector not only created new consumption habits but also created new opportunities for agents.

As the existing literature shows, e-commerce is a very important tool not only for the development of organizations, but particularly for the development of territories, and this relevance is especially important in regions where a significant set of constraints already exist, as is the case in low density regions [2].

Over the last few years, several authors have focused on the formalization and conceptualization of the concept of electronic commerce, but mainly on the possibilities associated with its application in contexts where economic, geographic or social factors may represent, in some way, an obstacle to the so-called traditional marketing of goods and services [7].

According to Cao et al. [16], the incorporation of complementary negotiation actions into the typical process of buying and selling through digital mechanisms has been the target not only of the attention of the scientific community [9, 10], but also of organizations that see an opportunity to be able to buy products/services at a more costeffective price, and to be able to offer their customers the ability to negotiate/customize the product or service they are trying to acquire, and in real time get feedback on their proposals [12].

\section{3 e-Commerce and Low-Density Regional Tourism}

Such as Boateng et al. [17] claimed a decade ago, and Awiagah et al. [18] currently confirm, e-commerce when used correctly can serve as a catalyst for the economic and social development of a region, as it allows for the range of economic operators to extend themselves virtually and at much lower costs than associated with traditional export initiatives.

The incorporation of e-commerce into (more or less developed) business activities related to tourism is assumed to be the key element for the sector's change and the assumption of the importance that the international dimension has for organizations and regions. This process of digitization, through the incorporation of mechanisms for the 
promotion and online sale of products and goods, is seen as more relevant and decisive in regions with lower levels of economic and social development [19].

Over the last few years, tourism has been evolving, proving the existence of new sectoral niches where the elements "inequality" and "disadvantage" are the support for a new set of tourism offers widely stimulated and mediated through digital platforms and whose sale is typically conducted online [20].

According to Chen and Tsao [21] and Rodrigues et al. [22], the use of electronic commerce as a mechanism to stimulate tourism is even more critical when in rural environments, as is the case in the Douro region, since the typical lack of capacity (technical, technological, functional, financial, etc.), greatly limits the business actions of tourism organizations located in these environments and consequently their ability to attract new customers and reach new markets.

\section{Functional Analysis of an Electronic Negotiation Platform for Tourism}

The identification and characterization of requirements refers to the process of verifying a given system's necessary features and its users' needs. Considering Anu et al. [23] argument concerning requirements analysis, a decision was made to identify, in a collaborative manner, all requirements inherent to an electronic negotiation platform that could serve the tourism sector, thus assuming that the developed system will achieve the necessary quality.

In order to formalize the software engineering process, we have performed a series of efforts towards analyzing the system to be developed. These efforts have resulted in the definition of the system architecture, a set of use cases (generalized into one single use case diagram representing a global perspective on the system's features and interactions) and a class diagram (represented in this manuscript by a simplified version that conceived the main entities supporting the system).

\subsection{Architecture Proposal}

A straightforward analysis of existing e-commerce and electronic negotiation platforms allowed us to perceive a common architecture alignment between all of them. Therefore, by implementing a collaborative system architecture design where the main Douro Valley stakeholders have been uniting efforts and giving their own inputs on what an electronic negotiation platform for tourism (in the referred region) should be, an architecture proposal has been reached (Fig. 1).

Considering that the work behind the present paper is an ongoing research effort, a previous version of the negotiation platform has already been subject to peer-review and has been considered extremely interesting for serving as the basis for the development of a software piece to mimic the presented component connections. 


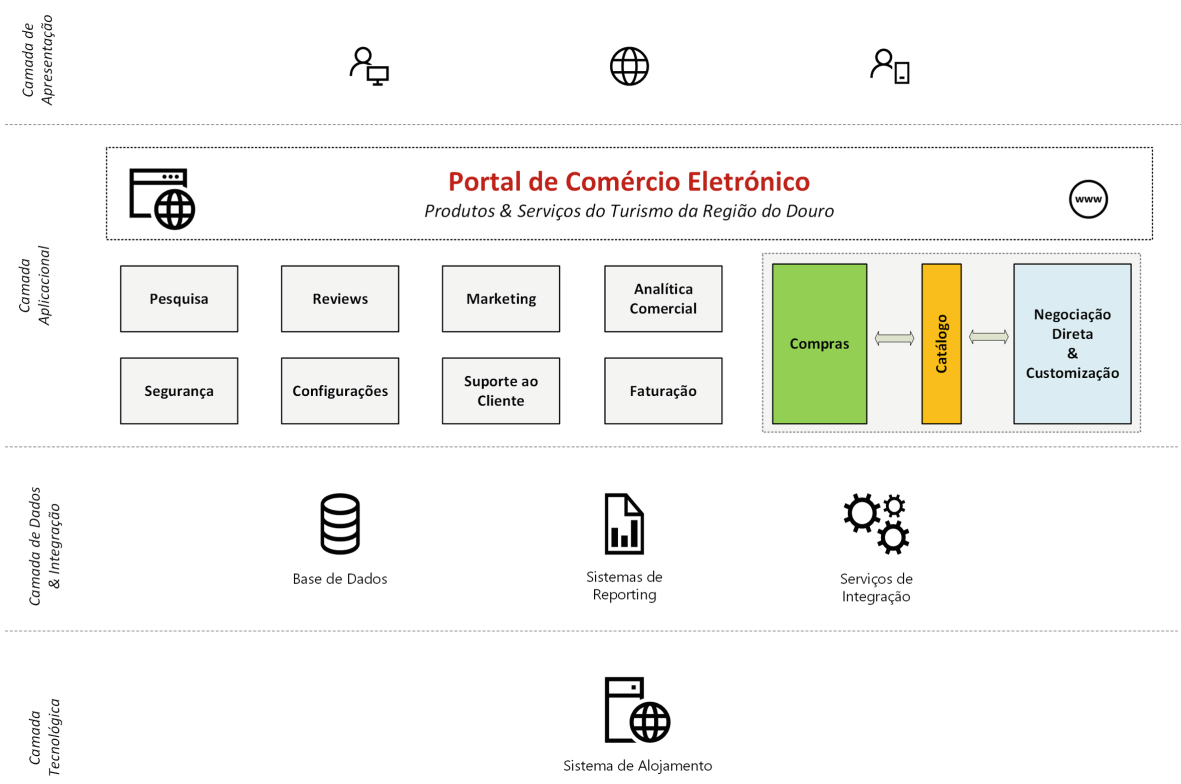

Fig. 1. Electronic negotiation platform architecture. Adapted from [22].

\subsection{Global Perspective on the System's Business Use Cases}

According to Huanca and Oré [24], the creation of business use cases that mimic the real use of the system to be developed might be considered one of the most important tasks associated with the analysis and specification of software (aka "software engineering"). Following these indications, we have identified a set of use cases that represent the main features that the electronic negotiation platform will involve and that are going to be made available on the platform we are going to implement.

As one can perceive in Fig. 2, we have identified four main user profile interactions with the system: the system administrator (with access to all available features), the operators (representing the tourism operators that are going to sell their products or services on the platform), the customers (who are those not only purchasing the available products but also presenting proposals for changes to existing products or to new products), and the visitor (who will in fact visit the region).

\subsection{Global Perspective on the System Class Diagram}

In order to understand the relations between the data objects that are going to be the basis of the electronic negotiation platform that we are going to develop, we have performed an analysis of the identified functional requirements and business use cases and were able to reach a set of conceptual classes (Fig. 3) and inherent relations.

By analyzing Fig. 3 we can perceive that for the platform we aimed to develop the main focus is the available offers (tourism products or services) and possible changes to 


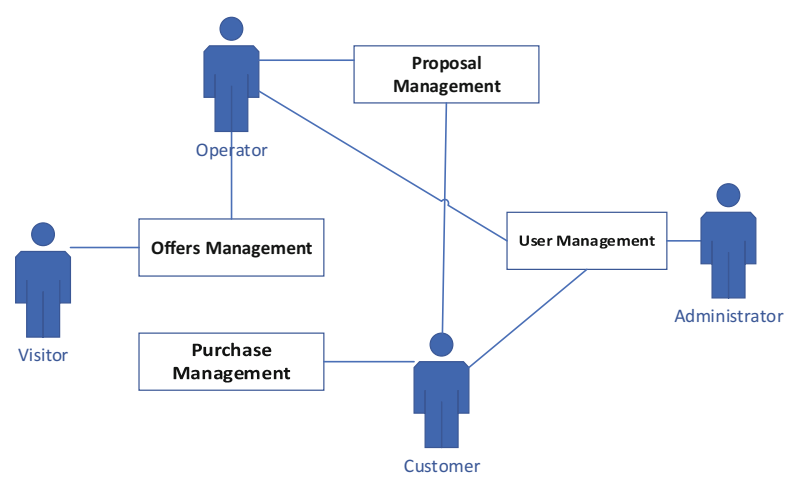

Fig. 2. Global perspective of the main business use cases identified.

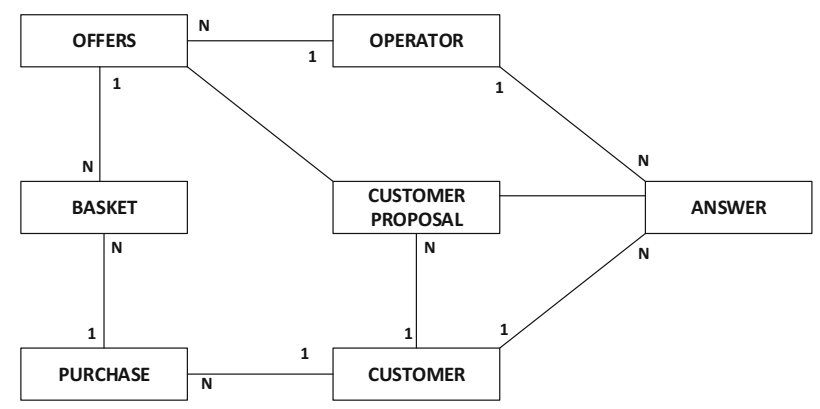

Fig. 3. Global approach to the electronic negotiation platform class diagram.

these offers that customers are willing to suggest, or even new customer proposed products to which registered operators can answer, thus the negotiation process.

\section{Proposal of an Electronic Negotiation Platform for Tourism}

\subsection{Technological Solution Used}

An online store, or a website that allocates an online store, can be implemented in one of two ways: (1) using content management system (CMS) systems; or (2) developing a customized solution from scratch.

If the e-store was built using CMS, the building process would be more linear and faster. However, given that the platform to be proposed has to implement a mechanism to support electronic negotiation between clients and vendors, and since in the light of our knowledge there are no modules for CMS that support this type of negotiation, we opted to develop an electronic trading platform for tourism (thus, a customized solution from scratch, as mentioned above). 
In this sense, and after a systematic analysis of the various tools and approaches available for the development of responsive web platforms, ASP.NET MVC (Model View Controller) was chosen as the base programming framework and the Microsoft Visual Studio tool as the development support instrument. ASP.NET is Microsoft's platform for developing Web applications in .NET, which allows you to generate pages that contain HTML, CSS, and JavaScript that contain server-side functionality. The relational database supporting the entire Web platform developed was implemented in a Data Base Management System (DBMS).

As can be seen in Fig. 4, from the home page, a client can access the various zones of the developed platform. These areas are coloured in blue or red. Areas with a blue colour represent the pages that a client can access without being authenticated by the system. The coloured areas in red refer to the pages where the client needs to authenticate to access their content. For a client to log in to the system, he or she can do one of the following. If he or she already has an account, it is necessary to enter account information on the login page. This data can be queried and changed when querying the profile after the authentication in the system has been made. If there is no account, it is necessary to access the registration page and create a new account.

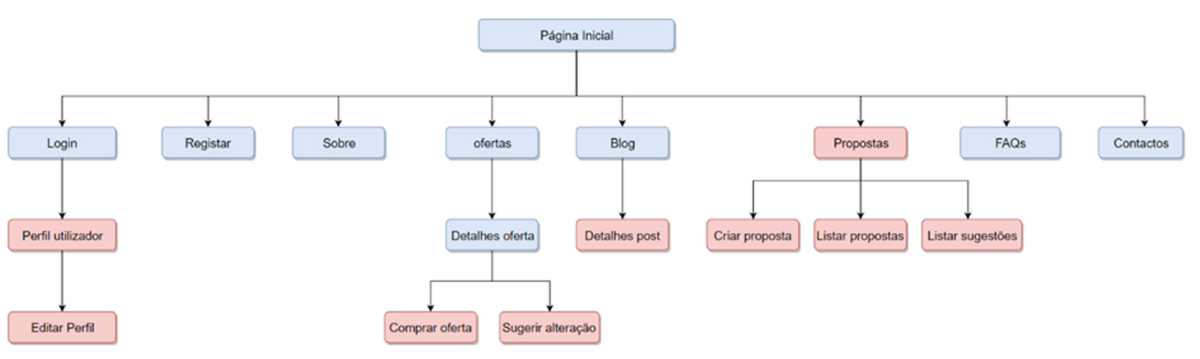

Fig. 4. Proposed prototype front-office navigation scheme.

The About page is intended to provide the customer with some information regarding the Douro area. In the zone of offers it is possible to consult all the active offers existing in the system for the various sectors of tourism. After seeing the details of the offer, the client can buy the tourist offer, or in case something does not suit his or her preferences, he or she can try to negotiate the same offer, suggesting some adjustments to it. All of these suggestions for change will be listed in the Proposals area. In addition, in this area, the client can also create and consult his or her own tourist proposal, which will be seen by all the operators belonging to the same sector. From the homepage, a client can also access the blog, where posts can be consulted which were created by the system administrator with news, curiosities, etc. The FAQs page is intended to help the customer with some questions regarding the platform by presenting some of the frequently asked questions. If the customer wants to contact the entity responsible, he or she can find all of the necessary information in the Contacts area. 
Figure 5 represents the home page of the developed platform. This page has as its main objective to present the platform to the client or potential clients. Since this will be the main navigation page of the platform, as well as the first page that potential customers will come into contact with, we chose to build it with a simple yet attractive design that works on any electronic device. It was also considered important to make the homepage dynamic (so that the information presented is always up to date), interactive and easy to navigate. An important part for browsing within the website is the menu. This menu consists of some important sections on the website such as information about the Douro region, tourist offers, and the blog, among others. In order to improve the user experience on the platform, it was decided to place several primary and secondary call-to-actions, such as "View Prices", "View Details", among others, in order to deepen and direct the users' navigation.

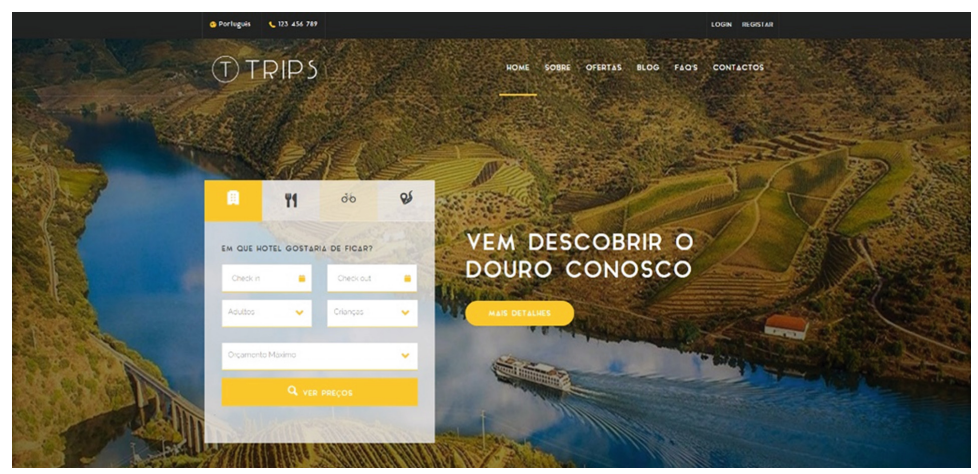

Fig. 5. Proposed prototype homepage layout.

Figure 6 represents the listing of tourist offers. Here a customer can search and consult all the existing tourist offers in the system. It was decided to split this page into two sections. In the first section, located on the left side, it was decided to provide a search panel, which allows the client to search the different tourist offers according to his or her criteria. The number of offers found is shown above. If the customer cannot find the tourist offer he or she is looking for, it is possible to create a proposal by clicking on the "Create Proposal" button. In the second section, located on the right hand side, is the list of tourist offers found. The information on the tourist offers listed is summarized, where only the name of the proposal is presented, as is a brief description of it, along with the price and the number of comments it has. If the client has an interest in any of the tourist offers, he or she simply has to click on the "Details" button to see more information about the offer and, if they exist, the comments on the offer.

Figure 7 is presented when the client wants to consult the details of a tourist offer. Here the customer can consult more information about the offer, such as more images, comments made by other customers, as well as contact information of the operator responsible for the tourism offer in question. The customer can also give his or her opinion when commenting on the tourist offer or when responding to another 
customer's comment. In case the customer is interested in the tourist offer he or she can proceed with the purchase by clicking on the "buy" button. If there is something that does not suit the possible future customer, there is an option to negotiate with the operator responsible for this offer. To do this, the client must press the "Suggest Change" button.

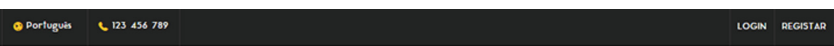

(T) TRIPS HOME SOBRe ofertas blog faAs contactos

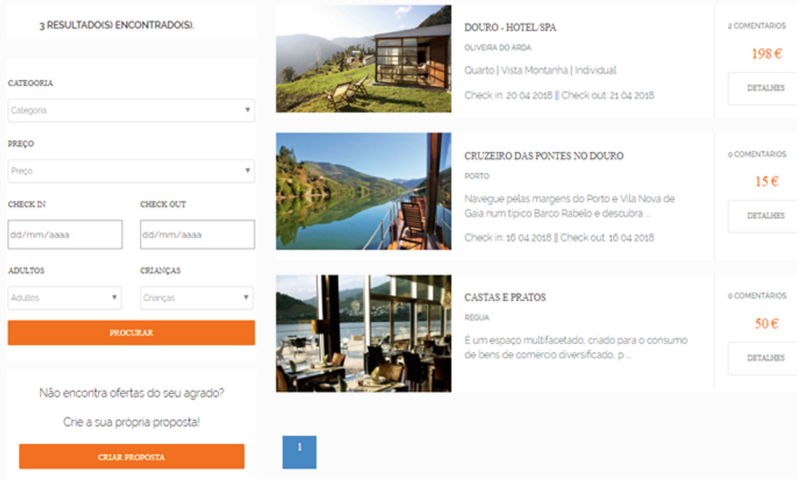

Fig. 6. Proposed prototype product listing page layout.

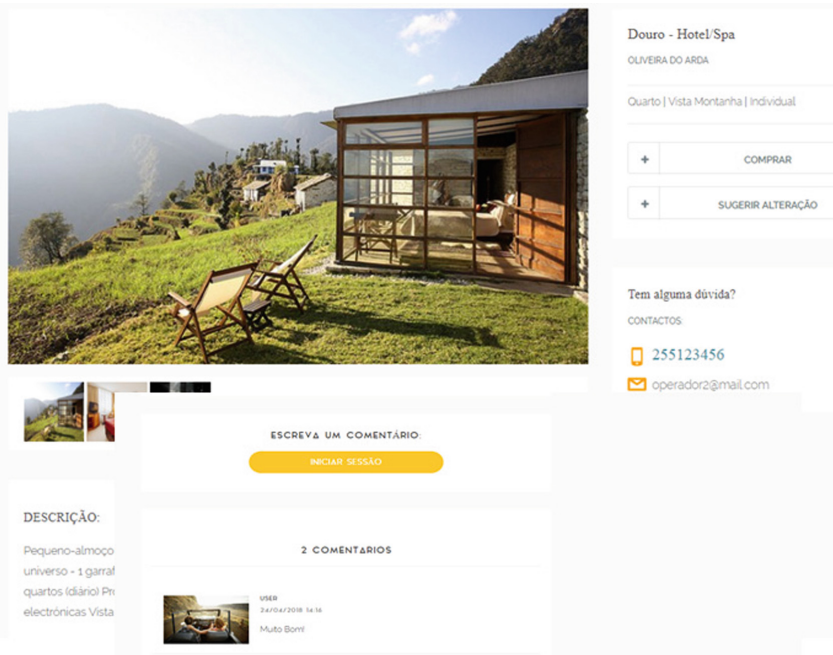

किस्रा

Fig. 7. Proposed prototype product edit page. 
When the customer clicks on the "Suggest Change" button, a form is shown (Fig. 8). When this form is opened, it will automatically be filled-in with the details of the tourist offer in question. Here the customer can consult the details of the offer and change some of the fields such as the price, the number of adults and children, among others. Note that some fields cannot be changed such as the title or description.

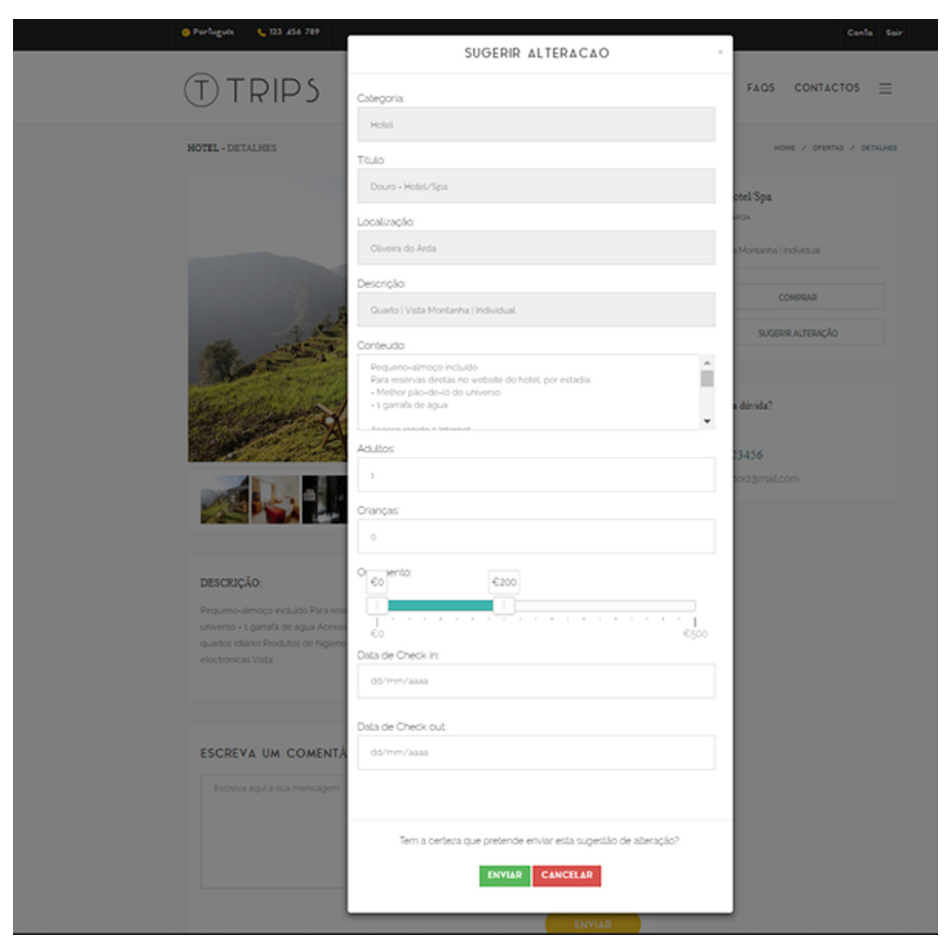

Fig. 8. Proposed prototype product change proposal.

When the customer considers that he or she has made the necessary changes to make the offer fit his/her needs, then one simply has to click on the "Submit" button to send the change suggestion. If he/she clicks on the "Cancel" button, the changed values are no longer valid, and the change suggestion is not sent. Once submitted, this suggestion for change can be consulted by the operator of the offer in question.

\section{Conclusions and Future Work}

The developed prototype intends to be an initial step towards the validation of the bidirectional e-Commerce paradigm applied to tourism, and particularly to tourism in low density regions. By drawing its developed features from a previously performed funcional and technical analysis, where software engineering techniques have been used, we believe that the presented output represents a step forward towards empowering 
even more the tourism operators of regions such as the Douro Valley, where despite the low levels of digital capabilities there is a proven interest in applying new technologies to the tourism sector as a way to address the new tourists' necessities.

In the future we would like to validate the developed prototype with a controlled test where real Douro Valley tourism operators are incorporated and pre-controlled samples of tourists are invited to be a part of the trial. This will allow us to perceive, first-off the acceptance level that both operators and tourists have for these technologies, and secondly the alignment between the developed solution and the actors' real necessities.

Acknowledgements. This paper was developed under Project I\&D DOUROTUR - Tourism and technological innovation in the Douro, operation number NORTE-01-0145-FEDER-000014, co-funded by Fundo Europeu de Desenvolvimento Regional (FEDER) through NORTE 2020 (Programa Operacional Regional do Norte 2014/2020).

\section{References}

1. Demirkan, H.: Special section: enhancing e-commerce outcomes with IT service innovations. Int. J. Electron. Commer. 19(3), 2-6 (2015)

2. Laudon, K.C., Traver, C.G.: E-commerce. Pearson (2013)

3. Hortala-Vallve, R., Llorente-Saguer, A., Nagel, R.: The role of information in different bargaining protocols. Exp. Econ. 16, 88-113 (2013)

4. Brennan, L.L.: Computer-Mediated Relationships and Trust: Managerial and Organizational Effects. IGI Global, Hershey (2007)

5. Kersten, G.E., Lai, H.: Negotiation support and e-negotiation systems: An overview. Group Decis. Negot. 16, 553-586 (2007)

6. Luo, X., Jennings, N.R., Shadbolt, N., Leung, H.-F., Lee, J.H.-M.: A fuzzy constraint based model for bilateral multi-issue negotiations in semi-competitive environments. Artif. Intell. J. 148, 53-102 (2003)

7. Luo, X., Sim, K.M., He, M.: A knowledge based system of principled negotiation for complex business contract. In: International Conference on Knowledge Science, Engineering and Management, pp. 263-279. Springer, Heidelberg (2013)

8. Braun, P., Brzostowski, J., Kersten, G., Kim, J.B., Kowalczyk, R., Strecker, S., Vahidov, R.: E-negotiation systems and software agents: methods, models, and applications. In: Intelligent Decision-Making Support Systems, pp. 271-300. Springer, Heidelberg (2006)

9. Kersten, G.: The science and engineering of e-negotiation: an introduction. In: Proceedings of the 36th Annual Hawaii International Conference on System Sciences, 2003, pp. 27-36. IEEE (2003)

10. Bichler, M., Kersten, G., Strecker, S.: Towards a structured design of electronic negotiations. Group Decis. Negot. 12, 311-335 (2003)

11. Insua, D.R., Holgado, J., Moreno, R.: Multicriteria e-negotiation systems for e-democracy. J. Multi-Criteria Decis. Anal. 12, 213-218 (2003)

12. Lempereur, A.P.: Innovation in teaching negotiation towards a relevant use of multimedia tools. Int. Negot. 9, 141-160 (2004)

13. Moore, D.A., Kurtzberg, T.R., Thompson, L.L., Morris, M.W.: Long and short routes to success in electronically mediated negotiations: group affiliations and good vibrations. Organ. Behav. Hum. Decis. Process. 77, 22-43 (1999) 
14. Teich, J.E., Wallenius, H., Wallenius, J., Zaitsev, A.: Designing electronic auctions: an internet-based hybrid procedure combining aspects of negotiations and auctions. Electron. Commer. Res. 1, 301-314 (2001)

15. Kersten, G., Lai, H.: Electronic negotiations: foundations, systems, and processes. In: Handbook of Group Decision and Negotiation, pp. 361-392. Springer, London (2010)

16. Cao, M., Luo, X., Luo, X.R., Dai, X.: Automated negotiation for e-commerce decision making: a goal deliberated agent architecture for multi-strategy selection. Decis. Support Syst. 73, 1-14 (2015)

17. Boateng, R., Heeks, R., Molla, A., Hinson, R.: E-commerce and socio-economic development: conceptualizing the link. Internet Res. 18, 562-594 (2008)

18. Awiagah, R., Kang, J., Lim, J.I.: Factors affecting e-commerce adoption among SMEs in Ghana. Inf. Dev. 32, 815-836 (2016)

19. Bui, T., Yen, J., Hu, J., Sankaran, S.: A multi-attribute negotiation support system with market signaling for electronic markets. Group Decis. Negot. 10, 515-537 (2001)

20. Rangaswamy, A., Shell, G.R.: Using computers to realize joint gains in negotiations: toward an "electronic bargaining table". Manag. Sci. 43, 1147-1163 (1997)

21. Chen, Y., Tsao, H.: A comparison of approaches of poverty alleviation through e-commerce. In: 2017 3rd International Conference on Information Management (ICIM), pp. 78-82. IEEE (2017)

22. Rodrigues, S., Goncalves, R., Teixeira, M.S., Martins, J., Branco, F.: Bidirectional ecommerce platform for tourism in low-density regions: the Douro Valley case study. In: 2018 13th Iberian Conference on Information Systems and Technologies (CISTI), pp. 1-5 (2018)

23. Anu, V., Hu, W., Carver, J., Walia, G., Bradshaw, G.: Development of a human error taxonomy for software requirements: a systematic literature review. Inf. Softw. Technol. (2018, in press)

24. Huanca, L., Oré, S.: Factores que afectan la precision de la estimacion del esfuerzo en proyectos de software usando Puntos de Caso de Uso. RISTI-Revista Ibérica de Sistemas e Tecnologias de Informação, 18-32 (2017) 